\title{
Efficacy and safety of lanthanum carbonate on chronic kidney disease-mineral and bone disorder in dialysis patients: a systematic review
}

\author{
Chenglong Zhang ${ }^{1}$, Ji Wen ${ }^{1}$, Zi Li ${ }^{1 *}$ and Junming Fan²
}

\begin{abstract}
Background: Chronic kidney disease-mineral and bone disorder (CKD-MBD) is a common complication in CKD patients, particularly in those with end-stage renal disease that requires dialysis. Lanthanum carbonate (LC) is a potent, non-aluminum, non-calcium phosphate binder. This systematic review evaluates the efficacy and safety of LC in CKD-MBD treatment for maintenance-dialysis patients.

Methods: A systematic review and meta-analysis on randomized controlled trials (RCTs) and quasi-RCTs was performed to assess the efficacy and safety of LC in maintenance hemodialysis or peritoneal dialysis patients. Analysis was performed using the statistical software Review Manager 5.1.
\end{abstract}

Results: Sixteen RCTs involving 3789 patients were identified and retained for this review. No statistical difference was found in all-cause mortality. The limited number of trials was insufficient to show the superiority of LC over other treatments in lowering vascular calcification or cardiovascular events and in improving bone morphology, bone metabolism, or bone turn-over parameters. LC decreased the serum phosphorus level and calcium $\times$ phosphate product $(\mathrm{Ca} \times \mathrm{P})$ as compared to placebo. LC, calcium carbonate $(\mathrm{CC})$, and sevelamer hydrochloride $(\mathrm{SH})$ were comparable in terms of controlling the serum phosphorus, $\mathrm{Ca} \times \mathrm{P}$ product, and intact parathyroid hormone (iPTH) levels. However, LC resulted in a lower serum calcium level and a higher bone-specific alkaline phosphatase level compared with CC. LC had higher total cholesterol and low-density lipoprotein (LDL) cholesterol levels compared with SH. LC-treated patients appeared to have a higher rate of vomiting and lower risk of hypercalcemia, diarrhea, intradialytic hypotension, cramps or myalgia, and abdominal pain. Meta-analysis showed no significant difference in the incidence of other side effects. Accumulation of LC in blood and bone was below toxic levels.

Conclusions: $L C$ has high efficacy in lowering serum phosphorus and IPTH levels without increasing the serum calcium. Current evidence does not show a higher rate of adverse effects for LC compared with other treatments, except for a higher incidence of vomiting. Moreover, LC accumulation in blood and bone was below toxic levels. Well-designed studies should be conducted to evaluate the long-term effects of LC.

Keywords: Lanthanum carbonate, Chronic kidney disease mineral and bone disorder, Hemodialysis, Peritoneal dialysis, Systematic review

\footnotetext{
*Correspondence: lizihx@163.com

'Department of nephrology, West China Hospital of Sichuan University, Chengdu, China

Full list of author information is available at the end of the article
} 


\section{Background}

With the progression of renal failure, patients frequently have disorders in bone and mineral metabolism [1]. This group of disorders is collectively called chronic kidney disease-mineral and bone disorder (CKD-MBD) and includes pathogenically linked biochemical abnormalities, bone diseases, and cardiovascular (CV) and soft tissue calcification [1]. Gradual decline in renal phosphorus clearance during CKD progression leads to hyperphosphatemia [2], which is a key factor in the development of MBD. Approximately $40 \%$ of dialysis patients reportedly suffer from hyperphosphatemia [3]. Increasing evidence shows that hyperphosphatemia promotes CV calcification [4] and is an important predictor of mortality in endstage renal disease (ESRD) patients undergoing dialysis [5-7]. Thus, lowering the serum phosphorus levels is a promising therapeutic goal.

Serum phosphorus levels in ESRD patients can be controlled by dietary restrictions, adequate dialysis schedule, and oral phosphate binders. A number of effective phosphate binders are currently available. For several years, aluminum- and calcium-based salts were widely used as phosphate binders because of their high efficacy and low price. However, aluminum has welldocumented toxic effects that can lead to osteomalacia or encephalopathy $[8,9]$, whereas large doses of calciumbased salts can contribute to CV calcification [10]. The use of aluminum- and calcium-free phosphate binders may address these issues. Sevelamer hydrochloride (SH) is another useful phosphate binder for ESRD patients $[11,12]$. However, its use is limited by the associated metabolic acidosis and gastrointestinal disorders as well as by the high dosage required to achieve adequate phosphate control [11-14].

Lanthanum carbonate (LC) is another phosphate binder that does not contain aluminum or calcium. Lanthanum is a naturally occurring "rare-earth" element that has a phosphate-binding capacity similar to that of aluminum. However, it is poorly absorbed in the human intestine and has an absolute oral bioavailability of only $0.00089 \%[15,16]$. Early studies in dialysis patients with ESRD demonstrated the effects of LC in lowering phosphorus levels during shortterm follow-up compared with a placebo and calcium carbonate (CC) $[17,18]$. Recently published studies observed the efficacy of LC in controlling the phosphorus level, reducing CV calcification [19], and in altering bone morphology [20-22] during a longer follow-up [21-24].

A previously published systematic review evaluated the efficacy and safety of LC in CKD patients and mainly focused on biochemical parameters [25]. We conducted a systematic review of the efficacy and safety of LC in ESRD patients undergoing dialysis, particularly in terms of long-term outcomes such as mortality, $\mathrm{CV}$ calcification, and bone disorder. The results were then compared with those of a placebo or other phosphate binders.

\section{Methods}

\section{Search strategy}

Randomized controlled trials (RCTs) or quasi-RCTs (in which allocation to treatment was obtained by alternation, alternate medical records, date of birth, or other predictable methods) of LC in patients with hemodialysis (HD) or peritoneal dialysis (PD) were searched in MEDLINE, EMBASE, the Cochrane Renal Group Specialised Register, and the Cochrane Central Register of Controlled Trials (CENTRAL) using the following criteria without any language restrictions: "lanthanum carbonate OR Fosrenol AND (dialysis OR hemodialysis OR peritoneal dialysis OR end stage renal disease". Animal or pediatric studies (with subjects below 18 years of age) were excluded without further review. Two authors independently screened the titles and abstracts of the remaining studies and discarded studies that were not applicable. However, studies and reviews that possibly include relevant data or information were initially retained. The latest date for the search was March 31, 2013.

\section{Studies}

All RCTs and quasi-RCTs that investigated the safety and effectiveness of LC in maintenance-HD or PD patients were considered eligible for inclusion.

\section{Participants}

ESRD patients who regularly receive $\mathrm{HD}$ or $\mathrm{PD}$, aged $\geq$ 18 years old, and did not use LC previously (at least $>1$ week) were included in this study. Patients with any of the following conditions were excluded:

1. Pregnancy or lactation.

2. Significant hypercalcemia [serum calcium $>11.0$ $\mathrm{mg} / \mathrm{dL}(2.75 \mathrm{mmol} / \mathrm{L})]$ or hypocalcemia [serum calcium < $7.9124 \mathrm{mg} / \mathrm{dL}(1.98 \mathrm{mmol} / \mathrm{L})]$.

3. Significant gastrointestinal disorders such as active peptic ulcer, ulcerative colitis and Crohn's disease, intestinal obstruction, or fecal impaction.

4. Malignancy.

5. Any exposure to other investigational drugs within 30 days prior to the start of the study.

\section{Interventions}

Intervention included the use of LC on ESRD patients receiving $\mathrm{HD}$ or $\mathrm{PD}$ regardless of dosage, mode of 
administration, or duration of treatment. The comparisons were as follows:

1. LC + routine treatment versus placebo + routine treatment.

2. $\mathrm{LC}+$ routine treatment versus calcium-based binders $(\mathrm{CBBs})+$ routine treatment.

3. $\mathrm{LC}+$ routine treatment versus $\mathrm{SH}+$ routine treatment.

4. $\mathrm{LC}+$ routine treatment versus other non-calcium binders (NCBs) or previous phosphate binders + routine treatment.

Routine treatment: HD or PD and supportive treatment. Supportive treatment included methods that treat underlying kidney or medical diseases or improve other disorders linked to kidney failure, such as anemia and hypertension. Other medications for CKD-MBD treatment, such as calcitriol and calcimimetics, could be used when needed, but the use of such medications should be applied parallelly both in the treatment group and the control group. Dietary restriction was not mandatory. Routine treatments in the LC group and the control group should be comparable.

\section{Outcome measures}

Primary outcomes

1. All-cause mortality.

2. Cardiovascular events.

Cardiovascular events were defined as fatal or nonfatal myocardial infarction, fatal or nonfatal cerebrovascular event (stroke), or the development of coronary artery disease.

\section{Secondary outcomes}

1. Vessel calcification (VC), including those of the aorta, coronary artery, and cardiac valves, as determined by spiral computed tomography.

2. Biochemical outcomes such as levels of serum phosphorus, serum calcium, calcium $\times$ phosphate product $(\mathrm{Ca} \times \mathrm{P})$, intact parathyroid hormone (iPTH), 1,25- $(\mathrm{OH}) \mathrm{D}_{3}, 25-(\mathrm{OH})_{2} \mathrm{D}_{3}$, total alkaline phosphatase (TAP), bone-specific alkaline phosphatase (BAP), and blood lipid.

3. Bone disorder (including bone morphology and bone metabolism).

4. Lanthanum contents in bone, liver, and blood.

5. Inflammatory biomarker such as C-reactive protein (CRP).

6. Side effects of medications.

\section{Quality assessment}

The quality of included studies was independently assessed by two authors who were not blind to authorship or journal of publication. The check list designed by the Cochrane Renal Group was used. Disagreements were resolved by consulting with an independent third party. The quality items assessed were the allocation concealment, blinding, intention-to-treat analysis, and completeness of follow-up. Blinding was assessed for investigators, participants, outcome assessors, and data analysts.

\section{Data extraction and management}

Data extraction was independently performed by two authors using standard data-extraction forms. When more than one publication of one study existed, reports were grouped together, and the most recent or most complete dataset was used. For studies that only displayed the results within diagrams from which data could not be retrieved, e-mails were sent to the authors to request for accessible data.

\section{Statistical analysis}

Analyses were performed using Review Manager 5.1. The results of dichotomous outcomes (all-cause mortality and cardiovascular events) were expressed as risk ratios (RR) with 95\% confidence intervals (CI). The mean difference (MD) was obtained when continuous scales of measurement were used to assess the treatment effects (e.g., serum calcium, $\mathrm{Ca} \times \mathrm{P}$, and $\mathrm{iPTH}$ ), whereas the standardized mean difference (SMD) was obtained when different scales were used. Between-study heterogeneity was assessed using the chi-square test. Random-effects analysis was used when $I^{2}>50 \%$, whereas fixed-effects analysis was used when $I^{2}<50 \%$ [26].

\section{Results}

\section{Search results}

Literature search identified 867 articles, 846 of which did not involve RCTs or quasi-RCTs and were thus excluded. Animal studies were also excluded. The full texts of 21 articles were analyzed, and an additional 3 were excluded because none of them met the inclusion criteria [27-29]. After excluding 2 repeatedly published studies [24,30], 16 articles [17-22,31-40] were identified and retained for this review. The 16 studies involved 3789 patients, 2100 of which were in the LC groups and 1689 in the control groups (241 in the placebo group, 534 in the CBB group, 205 in the SH group, and 709 in the NCB group) (Figure 1).

\section{Characteristics of the included studies}

The characteristics of the included studies are summarized in Table 1. Fourteen studies were prospective RCTs, whereas two were randomized crossover studies. All the included studies were published in English. The two crossover studies [32,33] combined the data of phase 1 and phase 2 (before and after exchange of treatment) together 


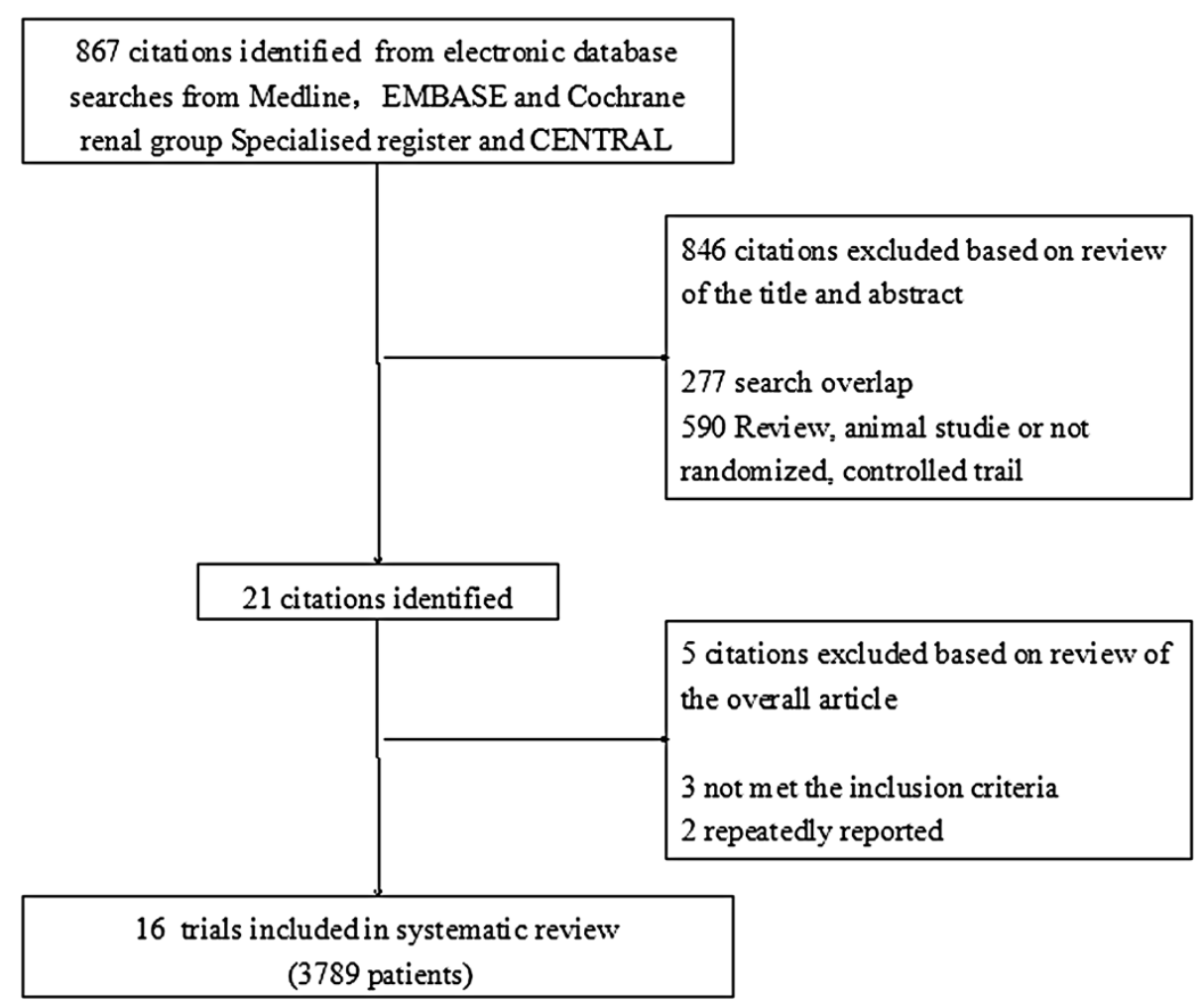

Figure 1 Procedure used for the trial selection.

to do the comparison but did not report the data for each phase. Three studies included HD and CAPD patients $[20,37,39]$. Eleven studies included only HD patients. One study included CAPD patients [39]. One study did not mention what kind of the dialysis method was used in the included patients [22]. Sample size ranged from 24 to 1359, and all but two studies had more than 500 participants [23,31].

The follow-up period ranged from 4 weeks to 3 years. One study [21] observed 33 patients in the LC group and 32 patients in the standard therapy group for 1 year and 32 and 24 patients for 2 years, respectively. Another study [22] followed up on 12 patients in the LC group and 12 in the CC group after 1 and 3 years, respectively. Only the data for the first year were complete and were extracted for meta-analysis. In summary, the follow-up periods of 9 studies were less than 24 weeks $[17,32-38,40]$, those of 4 studies ranged from 24 weeks to 1 year $[20,21,31,40]$, and those of 3 studies were longer than 1 year [19,22,23].

In terms of intervention, 6 studies compared LC with a placebo $[17,34,36-38,40], 6$ compared LC with CBBs [19,20,22,31,34,39], 2 compared LC with SH [32,33], and 2 compared LC with previous phosphate binders $[21,23]$.

Four studies $[17,20,21,32]$ used calcitriol in the routine treatment, whereas one study [17] used calcimimetics. The baseline of the usage of above medication were parallel between the LC group and the control group in all of the studies.

\section{Study quality}

A summary of the quality measurements is shown in Table 2. All 16 studies performed random allocation, but only $2[19,34]$ described the use of randomization. A considerable part of the studies included in this review were not blinded. Only 8 studies [17,32,34-38,40] reported blinding of patients and physicians, and 1 [19] reported blinding of outcome assessors. Intention-to-treat analysis was performed in 10 of the 16 studies, and fulfillment of follow-up was high in most of the studies except for two, which had long follow-up durations.

\section{Outcome}

\section{Effect on all-cause mortality}

Only two studies $[19,23]$ reported all-cause mortality of patients using $\mathrm{LC}$ and other phosphate binders. No significant difference was observed between the LC and the control in the risk of lowering all-cause mortality (2 studies, 1404 patients, RR: $0.85,95 \%$ CI: 0.69 to 1.04$)$.

\section{Effect on cardiovascular events}

Only one study [19] reported incidences of cardiovascular events. In the study, 3 in 22 LC-treated patients and 4 in 23 CC-treated patients experienced at least one 
Table 1 Characteristics of trials of LC for CKD-MBD in dialysis patients

\begin{tabular}{|c|c|c|c|c|c|}
\hline \multirow[t]{2}{*}{ Study } & \multicolumn{2}{|c|}{ Intervention } & \multirow[t]{2}{*}{ No. of patients } & \multirow[t]{2}{*}{ Duration (Week) } & \multirow[t]{2}{*}{ Dialysis methods } \\
\hline & LC group & Control group & & & \\
\hline Fouad Al-Baaj 2005 & LC $375-2250$ mg/d & Placebo & 36 & 4 & $\mathrm{HD}$ \\
\hline Melanie S. Joy 2003 & LC 375 mg, 750 mg, 1500 mg, 2250 mg, 3000 mg/day & Placebo & 93 & 4 & $\mathrm{HD}$ and CAPD \\
\hline Finn WF 2006 & LC $<3000$ mg/d (serum phosphate $\leq 5.9$ mg/dl) & pre-study phosphate binder (serum phosphate $\leq 5.9 \mathrm{mg} / \mathrm{dl}$ ) & 1359 & 104 & $H D$ \\
\hline Patrick. C 2003 & $\mathrm{LC}<3750 \mathrm{mg} / \mathrm{d}$ & $C C<9000 \mathrm{mg} / \mathrm{d}$ & 98 & 52 & HD \\
\hline N. D TOUSSAINT 2011 & LC (serum phosphate in the normal range) & CC (serum phosphate in the normal range) & 45 & 72 & $\mathrm{HD}$ and $\mathrm{CAPD}$ \\
\hline T.shigematsu 2008 & $\begin{array}{l}\text { LC+CC-liked placebo } 750,1500,2250 \mathrm{mg} / \mathrm{d} \text { (serum } \\
\text { phosphate at 3.5-5.5 mg/dl) }\end{array}$ & $\begin{array}{l}\text { CC+LC-liked placebo 1500, 3000, } 4500 \text { mg/d(serum } \\
\text { phosphate } 3.5-5.5 \mathrm{mg} / \mathrm{dl})\end{array}$ & 258 & 8 & $\mathrm{HD}$ \\
\hline H H Mallache 2008 & LC $<3000 \mathrm{mg} / \mathrm{d}$ (serum phosphate $\leq 5.9 \mathrm{mg} / \mathrm{dl}$ ) & Previous phosphate binder (serum phosphate $\leq 5.9 \mathrm{mg} / \mathrm{dl}$ ) & 65 & 52 & $H D$ \\
\hline T.shigematsu 2007 & LC 750 mg, 1500 mg, 2250 mg, 3000 mg/day & Placebo & 142 & 6 & $\mathrm{HD}$ \\
\hline Spasovski GB 2006 & LC $<3000$ mg/d (serum phosphate $<1.8 \mathrm{mmol} / \mathrm{L}$ ) & CC $<4000$ mg/d (serum phosphate $<1.8 \mathrm{mmol} / \mathrm{L}$ ) & 24 & 52 & Not describe \\
\hline A.J. Hutchison 2005 & LC 250-3000 mg/d & CC 1000-9000 mg/d & 767 & 25 & $\mathrm{HD}$ \\
\hline S.-S. Chiang 2005 & LC 375-3000 mg/d (can't change during study) & Placebo & 61 & 4 & $\mathrm{HD}$ \\
\hline Finn WF 2004 & LC 225 mg, 675 mg, 1350 mg, 2250 mg/day & Placebo & 144 & 6 & $H D$ \\
\hline Yong Kyu Lee 2013 & $\begin{array}{l}\text { LC } 1500 \mathrm{mg} \text { at start, regulate to control the serum } \\
\text { phosphate at } 3.5-5.5 \mathrm{mg} / \mathrm{dl}\end{array}$ & $\begin{array}{l}\text { CC } 3000 \mathrm{mg} \text { at start, regulate to control the serum } \\
\text { phosphate at } 3.5-5.5 \mathrm{mg} / \mathrm{dl}\end{array}$ & 50 & 24 & CAPD \\
\hline Xu 2013 & LC 1500 mg-3000 mg/day & Placebo & 230 & 4 & $\mathrm{HD}$ and CAPD \\
\hline Sprague S.M 2009 & LC 3,000 mg/day & SH 6,400 mg/day & 333 & 4 & $\mathrm{HD}$ \\
\hline Kasai S 2012 & LC 375-2250 mg/day & SH 750-9000 mg/day & 84 & 13 & $H D$ \\
\hline
\end{tabular}


Table 2 Summary of quality measures of included studies

\begin{tabular}{|c|c|c|c|c|c|c|c|c|}
\hline & $\begin{array}{l}\text { Randomisation } \\
\text { method }\end{array}$ & $\begin{array}{l}\text { Allocation } \\
\text { concealment }\end{array}$ & $\begin{array}{l}\text { Blinding: } \\
\text { Participants }\end{array}$ & $\begin{array}{l}\text { Blinding: } \\
\text { Investigators }\end{array}$ & $\begin{array}{l}\text { Blinding: } \\
\text { Outcome } \\
\text { assessors }\end{array}$ & $\begin{array}{l}\text { Blinding: Data } \\
\text { assessors }\end{array}$ & ITT & $\%$ Follow-up \\
\hline Fouad AI-Baaj 2005 & NS & NS & Yes & Yes & No & No & No & 94 \\
\hline Melanie S. Joy 2003 & NS & NS & Yes & Yes & No & No & Yes & 87 \\
\hline Finn WF 2006 & NS & NS & No & No & No & No & No & 38 \\
\hline Patrick.C 2003 & NS & NS & No & No & No & No & Yes & 64 \\
\hline N. D TOUSSAINT 2011 & $\begin{array}{l}\text { Computer-generated } \\
\text { random numbers }\end{array}$ & Yes & No & No & No & Yes & Yes & 67 \\
\hline T.shigematsu 2008 & NS & NS & Yes & Yes & No & No & Yes & 99 \\
\hline H H Mallache 2008 & NS & NS & No & No & No & No & No & 47 \\
\hline T.shigematsu 2007 & $\begin{array}{l}\text { A single stream } \\
\text { scheme }\end{array}$ & Yes & Yes & Yes & No & No & No & 91 \\
\hline Spasovski GB 2006 & NS & NS & NS & NS & NS & NS & No & 83 \\
\hline A.J. Hutchison 2005 & NS & NS & No & No & No & No & Yes & 58 \\
\hline S.-S. Chiang 2005 & NS & NS & Yes & Yes & No & No & Yes & 69 \\
\hline Finn WF 2004 & NS & NS & Yes & Yes & No & No & Yes & 63 \\
\hline Yong Kyu Lee 2013 & NS & NS & NS & NS & NS & NS & No & 69 \\
\hline Xu 2013 & NS & NS & Yes & Yes & NS & NS & Yes & 99 \\
\hline Sprague, S.M 2009 & NS & NS & Yes & Yes & NS & NS & Yes & 90 \\
\hline Kasai, S 2012 & NS & NS & NS & NS & NS & NS & Yes & 95 \\
\hline
\end{tabular}

NS: Not Stated.

cardiovascular event. No significant difference was observed between the LC and CBB groups in terms of the risk of lowering cardiovascular events (1 study, 45 patients, RR: $0.78,95 \% \mathrm{CI}: 0.20$ to 3.11 ).

\section{Effect on vessel calcification}

One study [19] reported an improvement in aortic vascular calcification. In the study, patients were randomized to either LC $(n=22)$ or CC $(n=23)$. Patients in the LC group showed significantly less aortic VC progression than those in the CC group (difference from baseline $-99.6 \mathrm{HU}, 95 \% \mathrm{CI}:-150.5$ to $-48.8, p<0.001)$. None of the trials reported calcification of the coronary artery or cardiac valves.

\section{Effects on biochemical outcomes}

Fourteen studies [19-22,31-40] compared the serum phosphorus level after treatment with LC with that of a control. Six studies reported the results in diagrams only and did not provide definite figures. The figures for two studies were eventually acquired by writing the authors $[34,35]$. The remaining four studies were not included because the authors did not respond [20,21,23,32]. The serum phosphorus levels were compared in 10 other studies, 5 of which compared LC with a placebo [34,36-38,40], 4 compared LC with CC [19,22,35,39], and 1 compared LC with SH [33]. Meta-analysis showed that LC significantly lowered the serum phosphorus level compared with the placebo ( 5 studies, 562 patients, MD: -0.64 , 95\% CI: 0.78 to -0.50 ), whereas no difference was observed between the LC and CC groups (4 studies, 377 patients, MD: $0.09,95 \%$ CI: 0.00 to 0.19$)$ and between the LC and SH groups (1 study, 84 patients, MD: -0.09 , 95\% CI: 0.19 to 0.01 ) (Figure 2).

Seven studies [22,31,33-35,37,39] provided reports on serum calcium levels. Analysis of their results showed no difference between LC and the placebo (2 studies, 235 patients, MD: 0.05 , 95\% CI: -0.02 to 0.12$)$ or between LC and SH (1 study, 84 patients, MD: 0.02, 95\% CI -0.03 to 0.07$)$. CC-treated patients had higher calcium levels than those treated with LC (4 studies, 1099 patients, MD: -0.12 , 95\% CI: -0.15 to -0.09 ) (Figure 3).

Seven studies $[19,31,33,34,36,37,39]$ reported Calcium $\times$ Phosphate Product levels and showed that patients treated with LC had lower $\mathrm{Ca} \times \mathrm{P}$ than those treated with a placebo (3 studies, 271 patients, MD: -1.43 , 95\% CI: -2.04 to -0.81$)$. By contrast, no significant difference was observed between LC and CC (3 studies, 862 patients, MD: $0.14,95 \% \mathrm{CI}:-0.30$ to 0.03 ) and between $\mathrm{LC}$ and $\mathrm{SH}$ (1 study, 84 patients, MD: $-0.16,95 \%$ CI -0.39 to 0.07 ) (Figure 4).

Four studies [22,33-35,37] reported the change in iPTH levels and showed that LC-treated patients achieved lower iPTH levels than those treated with placebos (2 studies, 235 patients, MD: $-95.04,95 \%$ CI: -151.10 to -38.98$)$. By contrast, no significant differences were observed between 


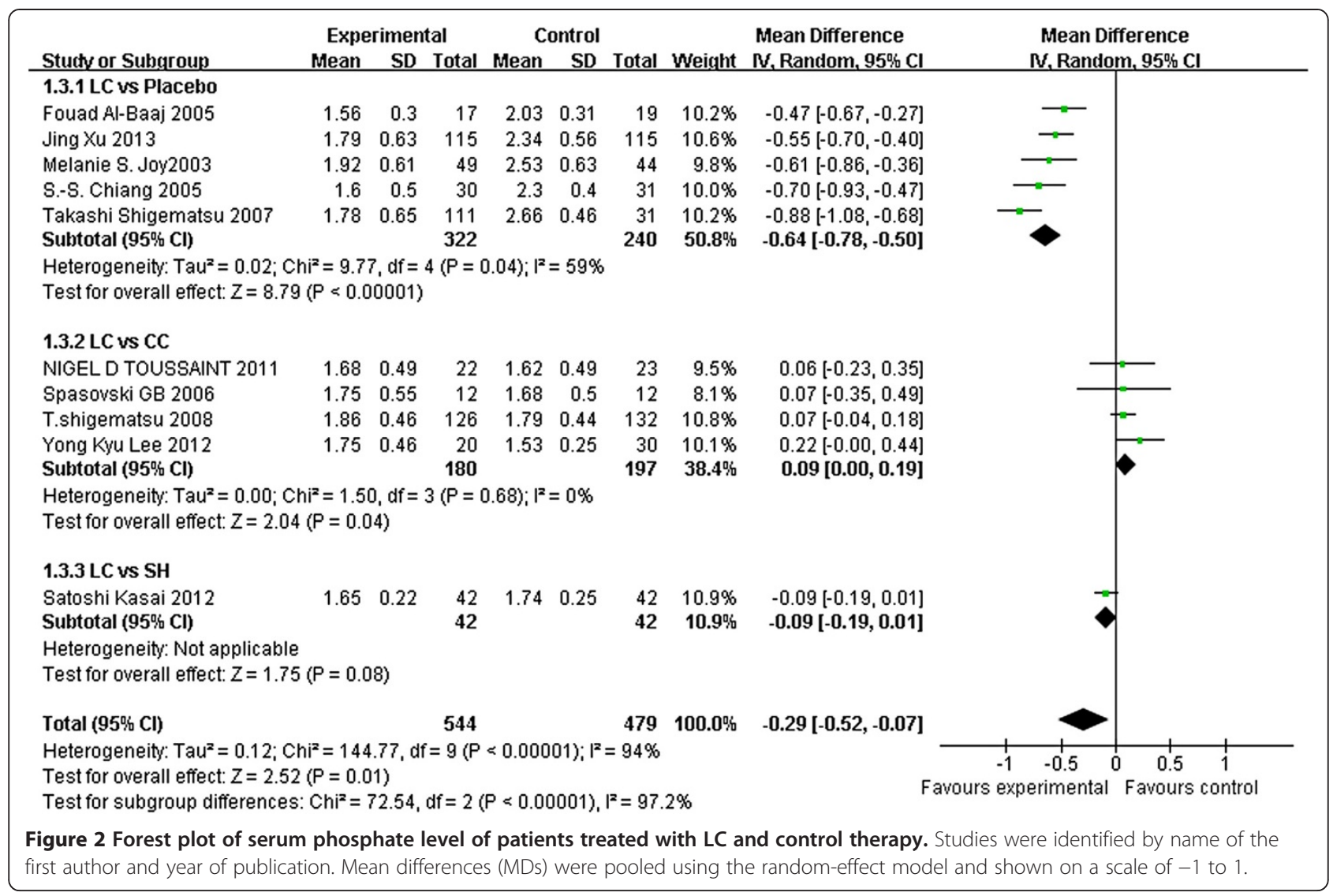

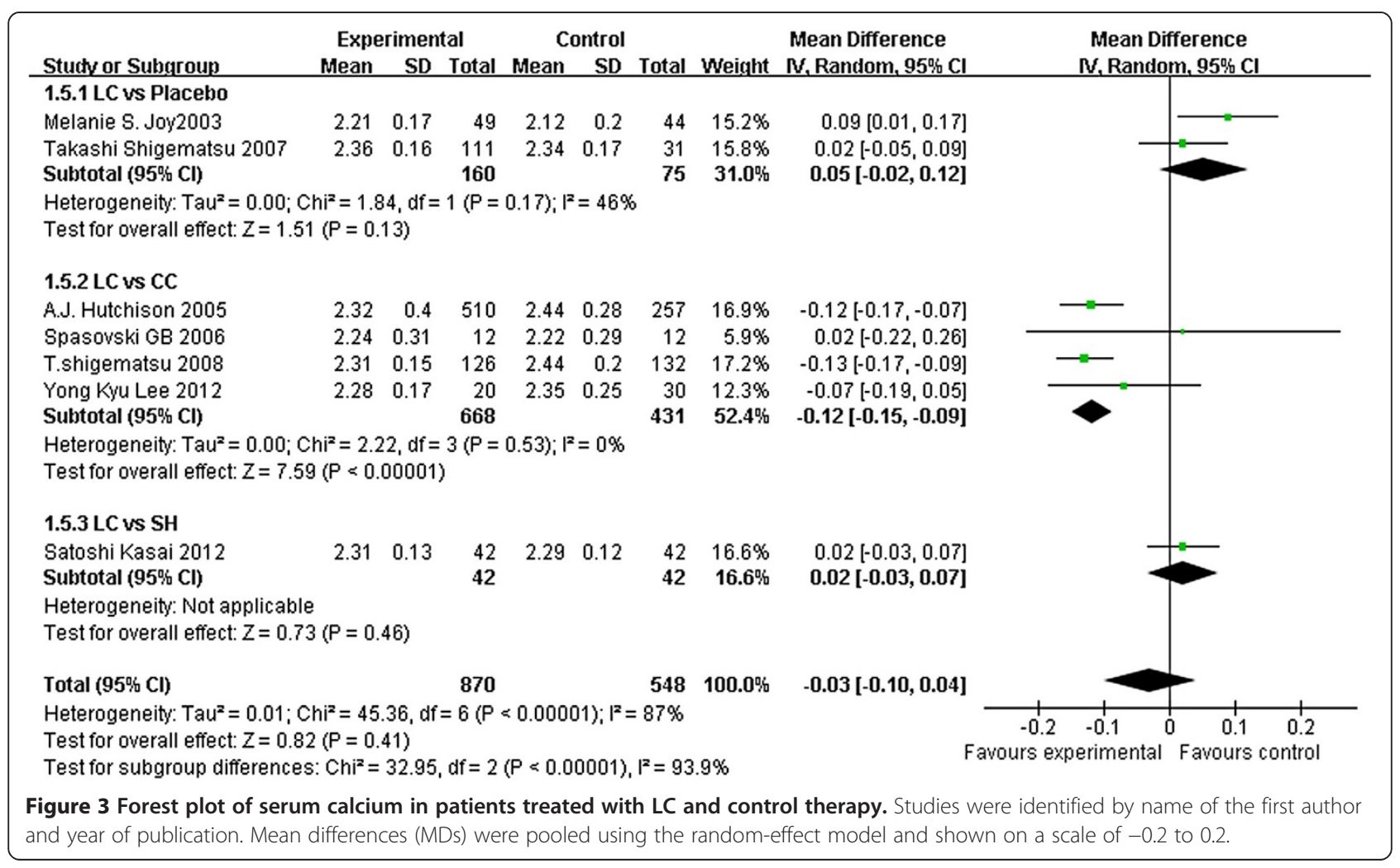




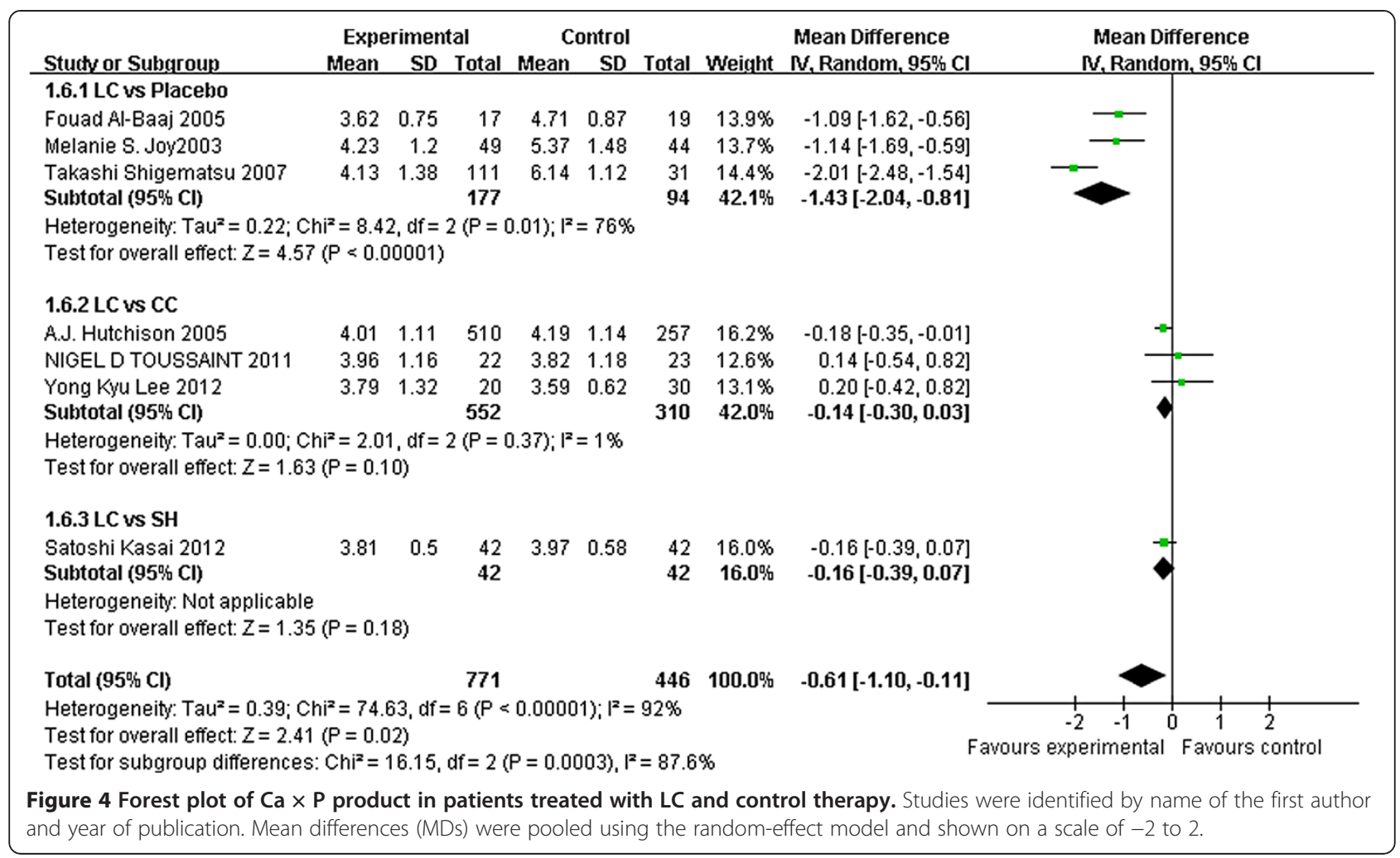

LC and CC (2 studies, 282 patients, MD: 112.12, 95\% CI: 23.43 to 247.66 ) and between LC and SH (1 study, 84 patients, MD: $14.30,95 \% \mathrm{CI}:-27.83$ to 56.43 ) (Figure 5).

Spasovski et al. [22] followed up the patients at 1 or 3 years after treatment and showed no difference between the 1,25- $(\mathrm{OH}) \mathrm{D}_{3}$ levels of the LC and CC groups (1 study, 24 patients, $\mathrm{MD}:-0.80,95 \% \mathrm{CI}:-27.16$ to 25.56$)$. In a similar manner, no difference was observed between the 25- $(\mathrm{OH})_{2} \mathrm{D}_{3}$ levels (1 study, 24 patients, MD: 11.00 , 95\% CI: -6.21 , to 28.21 ) and TAP (1 study, 24 patients, MD:

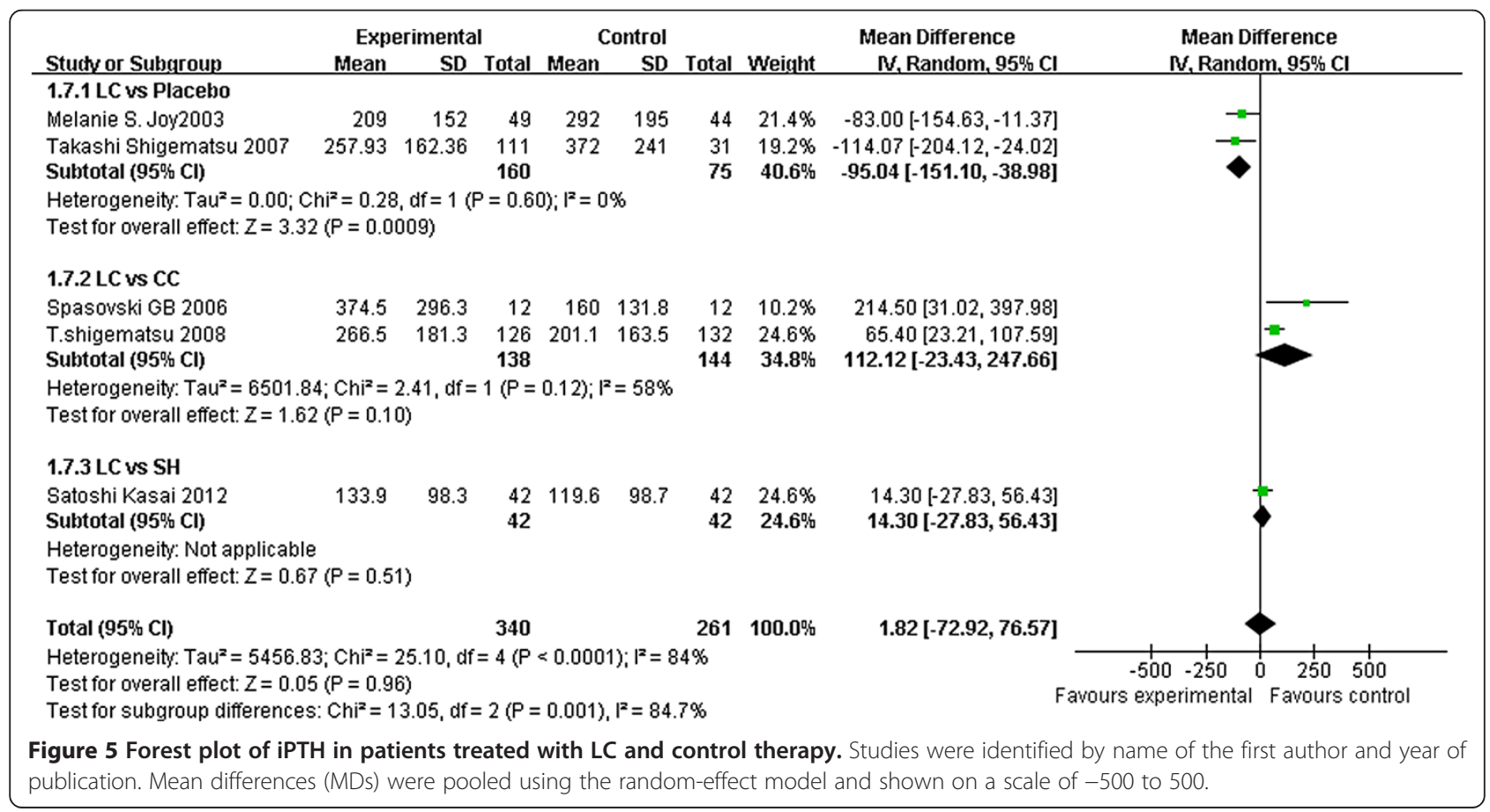


7.80, 95\% CI: -31.73 to 47.33$)$ of the LC and CC groups. One study compared LC with $\mathrm{SH}$ and showed no difference in TAP (1 study, 84 patients, MD: 7.00, 95\% CI: 55.03 to 69.03$)$. Three studies $[22,23,31]$ reported the BAP levels; patients in the LC group had higher BAP than those who continued to use the previous phosphate binder (1 study, 1359 patients, MD: 4.90, 95\%: CI 2.73 to 7.07 ). By contrast, no difference was found between the BAP levels of LC and CC (1 study, 24 patients, MD: 2.50, 95\% CI: -10.44 to 15.44 ) and between LC and SH (1 study, 84 patients, MD: $1.30,95 \% \mathrm{CI}:-6.55$ to 9.15$)$.

The results also showed that when compared with the $\mathrm{SH}$ group, the LC group had higher levels of total cholesterol (1 study, 84 patients, MD: 25.00, 95\% CI: 12.17 to 37.83 ) and LDL cholesterol (1 study, 84 patients, MD: 20.00, 95\% CI: 10.16 to 29.84) [33]. Other studies did not investigate the difference between the lipid levels of the LC and control groups (placebo, CC, or previous phosphate binders).

\section{Bone disorder}

Three studies [20-22] involved patients who received at least one bone biopsy. However, these studies used different parameters that a meta-analysis was not possible. D'Haese et al. [20] performed bone biopsy in 33 patients in the LC group and 30 patients in the $\mathrm{CC}$ group at the baseline and one year after treatment, respectively. The subtypes of bone diseases were similarly distributed in both groups at the baseline. In the LC group, the number of patients with renal osteodystrophy (ROD) decreased from $12(36 \%)$ at the baseline to 6 in the 1 -year follow-up (18\%), whereas that in the calcium group increased from $13(43 \%)$ to 16 (53\%). One patient in the LC group and 6 in the CC group evolved toward adynamic bone.

Malluche et al. [21] performed bone biopsy in 32 patients in the LC group and 33 patients in the $\mathrm{CC}$ group at the baseline and 1 and 2 years after treatment. Their results showed that under similar phosphorus control, the LC group showed improvements in the bone turnover and bone volume; the improvements were particularly significant in the 1-year and 2-year groups, respectively. No significant change in the bone turnover or bone volume was observed in the standard phosphate-binder therapy group. Spasovski et al. [22] followed up on patients 1 or 3 years after treatment and did not observe any differences in the osteoblast numbers and mineral apposition rates between the LC and CC groups.

\section{Lanthanum contents in bone, liver, and blood}

Seven studies $[20,22,23,31,34,37,38]$ measured the plasma or serum lanthanum level. Most of the results showed slightly increased lanthanum levels in the blood of the LC groups but did not indicate any statistical difference, except in one study [22], which reported significantly higher plasma lanthanum levels in the LC group compared with that in the CC group. No study reported lanthanum contents exceeding the limit of quantification, a condition that would be harmful to the body. Three studies [20-22] detected the lanthanum content in the bone and showed no significant difference in the bone lanthanum contents between LC and control group. Metaanalysis was not performed because the unit for lanthanum content varied among the studies. No study reported the lanthanum content in the liver or other organs.

\section{Inflammatory biomarker}

None of trials reported any inflammatory biomarker such as CRP.

\section{Side effects of medications}

Only 4 studies [19-21,39] did not evaluate the side effects of medications. Results showed that LC had a lower risk of diarrhea when compared with placebo (4 studies, 395 patients, RR 0.31 , 95\% CI 0.15 to 0.65 ). When compared with CBBs, there was a higher rate of vomiting (2 studies, 1058 patients, RR 1.51, 95\% CI 1.08 to 2.12) and a lower rate of hypercalcaemia (5 studies, 1220 patients, RR $0.12,95 \%$ CI 0.04 to 0.38 ) in patient treated with LC. Our meta-analysis also showed that when compared with previous phosphate binders, there was a lower rates of intradialytic hypotension (1 study, 1359 patients, RR: 0.66, 95\% CI: 0.53 to 0.82 ), cramps or myalgia (1 study, 1359 patients, RR: $0.76,95 \%$ CI: 0.63 to 0.92 ), and abdominal pain (1 study, 1359 patients, RR: 0.73, 95\% CI: 0.59 to 0.91 ) in LC-treated patient. No significant differences were found in the incidences of nausea, constipation, bronchitis, dyspepsia, rhinitis, pruritus, and dialysis complications (Table 3).

\section{Discussion}

A comprehensive search for RCTs was performed to evaluate the efficacy and safety profile of lanthanum in maintenance-dialysis patients. A total of 16 trials involving 3789 patients met our criteria and were enrolled in our meta-analysis. Our results show no lanthanum-induced decrease in all-cause mortality or cardiovascular events. Only one RCT [19] reported on vascular calcification and showed that lanthanum delayed the progression of aortic calcification compared with CC. Lanthanum efficiently lowered the serum phosphorus, $\mathrm{Ca} \times \mathrm{P}$, and iPTH levels compared with placebos. Moreover, lanthanum showed equal efficiency in lowering serum phosphorus, $\mathrm{Ca} \times \mathrm{P}$, and iPTH levels as calcium bicarbonate but with a lower serum calcium level. No statistical differences in 1,25$(\mathrm{OH}) \mathrm{D}_{3}, 25-(\mathrm{OH})_{2} \mathrm{D}_{3}$ and TAP were observed between lanthanum and CC. However, lanthanum caused a 
Table 3 Side-effects of medications

\begin{tabular}{|c|c|c|c|c|c|c|}
\hline & Fixed-effe & del & Random-effe & odel & Hete & eity \\
\hline & RR $(95 \% \mathrm{Cl})$ & $P$ value & RR $(95 \% \mathrm{Cl})$ & $P$ value & $P$ value & $I^{2}(\%)$ \\
\hline Vomiting & $1.06[0.91,1.23]$ & 0.45 & $1.22[0.81,1.84]$ & 0.33 & 0.04 & $54 \%$ \\
\hline LC vs Placebo & $2.35[0.95,5.80]$ & 0.06 & $1.87[0.55,6.37]$ & 0.32 & 0.22 & $32 \%$ \\
\hline LC vs CBBs & $1.51[1.08,2.12]$ & 0.02 & $1.51[1.08,2.11]$ & 0.02 & 0.37 & $0 \%$ \\
\hline LC vs previous phosphate binders & $0.90[0.76,1.06]$ & 0.20 & $0.90[0.76,1.06]$ & 0.20 & - & - \\
\hline Diarrhea & $0.79[0.68,0.93]$ & 0.003 & $0.69[0.40,1.18]$ & 0.17 & 0.001 & $70 \%$ \\
\hline LC vs Placebo & $0.31[0.15,0.65]$ & 0.002 & $0.29[0.14,0.62]$ & 0.001 & 0.53 & $0 \%$ \\
\hline LC vs CBBs & $1.29[0.84,1.98]$ & 0.24 & $1.29[0.84,1.98]$ & 0.24 & - & - \\
\hline LC vs previous phosphate binders & $0.75[0.63,0.90]$ & 0.001 & $0.75[0.63,0.90]$ & 0.001 & - & - \\
\hline Nausea & $1.03[0.91,1.17]$ & 0.61 & $1.25[0.85,1.84]$ & 0.26 & 0.06 & $52 \%$ \\
\hline LC vs Placebo & $2.06[0.82,5.16]$ & 0.12 & $1.60[0.49,5.16]$ & 0.43 & 0.26 & $27 \%$ \\
\hline LC vs CBBs & $1.42[1.01,2.01]$ & 0.05 & $1.80[0.70,4.64]$ & 0.22 & 0.09 & $66 \%$ \\
\hline LC vs previous phosphate binders & $0.93[0.81,1.07]$ & 0.32 & $0.93[0.81,1.07]$ & 0.32 & - & - \\
\hline Constipation & $0.72[0.46,1.12]$ & 0.14 & $0.70[0.36,1.35]$ & 0.29 & 0.23 & $31 \%$ \\
\hline Hypercalcaemia & $0.10[0.06,0.16]$ & $<0.00001$ & $0.12[0.04,0.38]$ & 0.0002 & 0.009 & $71 \%$ \\
\hline LC vs CBBs & & & & & & \\
\hline Intradialytichypotension & $0.70[0.58,0.85]$ & 0.0004 & $0.72[0.54,0.96]$ & 0.03 & 0.28 & $21 \%$ \\
\hline LC vs Placebo & $3.10[0.34,28.17]$ & 0.31 & $3.10[0.34,28.17]$ & 0.31 & - & - \\
\hline LC vs CBBs & $0.83[0.51,1.36]$ & 0.47 & $0.83[0.51,1.36]$ & 0.47 & - & - \\
\hline LC vs previous phosphate binders & $0.66[0.53,0.82]$ & 0.0002 & $0.66[0.53,0.82]$ & 0.0002 & - & - \\
\hline Cramps or Myalgia & $0.81[0.68,0.97]$ & 0.02 & $0.83[0.65,1.07]$ & 0.15 & 0.32 & $13 \%$ \\
\hline LC vs Placebo & $1.29[0.38,4.35]$ & 0.68 & $1.29[0.38,4.35]$ & 0.68 & - & - \\
\hline LC vs CBBs & $1.12[0.64,1.95]$ & 0.69 & $1.12[0.64,1.95]$ & 0.69 & - & - \\
\hline LC vs NCBs & $0.76[0.63,0.92]$ & 0.005 & $0.76[0.63,0.92]$ & 0.005 & - & - \\
\hline Abdominal pain & $0.75[0.61,0.92]$ & 0.006 & $0.74[0.60,0.91]$ & 0.004 & 0.64 & $0 \%$ \\
\hline LC vs Placebo & $2.14[0.40,11.44]$ & 0.37 & $1.93[0.35,10.55]$ & 0.45 & 0.56 & $0 \%$ \\
\hline LC vs CBBs & $0.60[0.18,2.00]$ & 0.40 & $0.60[0.18,2.00]$ & 0.40 & - & - \\
\hline LC vs previous phosphate binders & $0.73[0.59,0.91]$ & 0.004 & $0.73[0.59,0.91]$ & 0.004 & - & - \\
\hline Bronchitis & $0.82[0.66,1.03]$ & 0.08 & $0.82[0.66,1.03]$ & 0.08 & 0.97 & $0 \%$ \\
\hline Dyspepsia & $0.24[0.09,0.61]$ & 0.003 & $0.21[0.04,1.17]$ & 0.007 & 0.13 & $52 \%$ \\
\hline LC vs Placebo & & & & & & \\
\hline Rhinitis & $1.20[0.69,2.08]$ & 0.52 & $1.20[0.69,2.08]$ & 0.52 & 0.64 & $0 \%$ \\
\hline Pruritus & $4.04[0.56,29.27]$ & 0.17 & $3.84[0.48,30.48]$ & 0.20 & 0.55 & $0 \%$ \\
\hline LC vs Placebo & & & & & & \\
\hline Dialysis complication & $0.68[0.39,1.17]$ & 0.16 & $0.67[0.38,1.16]$ & 0.15 & 0.39 & $0 \%$ \\
\hline
\end{tabular}

statistically significant increase in the BAP level compared to previous phosphate binder. No differences were observed between $\mathrm{SH}$ and LC in controlling serum phosphorus, serum calcium, TAP, and BAP levels. However, $\mathrm{SH}$ reduced the total cholesterol and the LDL cholesterol levels. The efficacy of lanthanum on bone disorder was reported in only a few studies, and different parameters were used. Thus, our meta-analysis cannot draw reliable conclusions.
The two trials that observed all-cause mortality reported no difference in the risks of all-cause mortality between lanthanum and calcium bicarbonate [19] or standard therapy (without lanthanum) [23]. Wilson et al. [24] performed a trial involving 1354 patients and conducted follow-up examinations for 40 months. The study contributed $98.9 \%$ of the weight in our all-cause mortality analysis because of its large sample size. The study found no significant difference between the overall 
mortality rates of the LC treatment [19.9\% (135/680)] and standard therapy [23.3\% (157/674)]. Subgroup analysis showed that the mortality for patients aged $>65$ years was significantly lower in the LC treatment than in the standard therapy. This trend is highly similar to that of the Dialysis Clinical Outcomes Revisited (DCOR) study [41], which is the largest randomized comparatorcontrolled trial that assessed the mortality risks of noncalcium-based binders (sevelamer) and CC.

Vascular calcification is a common and severe problem associated with mortality in adult ESRD patients [42]. LC was demonstrated to attenuate the progression of vascular calcification in several animal models [43,44]. In the present analysis, only one trial [19] observed this outcome and reported that compared with $\mathrm{CC}$, lanthanum carbonate was associated with the reduced progression of aortic calcification in $30 \mathrm{HD}$ patients for over 18 months. Additional clinical studies involving large sample sizes and long-term follow-up must be conducted to determine whether lanthanum confers the advantage of inhibiting vascular calcification to dialysis patients. A prospective, largescale observational study [Study of Hyperphosphatemia in CKD5D Patients Undergoing Hemodialysis (STOP-HD trial): UMIN-ID 000002002] is currently underway to confirm the inhibitory effect of LC on vascular calcification. The results of this study are being anticipated.

A small number of trials performed bone biopsy; however, the efficiency on bone disorder was difficult to evaluate. Two trials $[20,21]$ found improvements in renal osteodystrophy in lanthanum-treated patients compared with those treated with $\mathrm{CC}$ or with their previous phosphate binders (without lanthanum). However, another trial [22] showed no difference between the two binders. D'Haese et al. [20] found that the number of patients with renal osteodystrophy decreased in the lanthanum group, whereas that in the CC group increased. Malluche et al. [21] found an improvement in bone turnover during the first year as well as a significant improvement in bone volume during the second year. By contrast, Spasovski et al. [22] found no significant differences in the osteoblast number, bone formation rate, osteoid volume, or mineral apposition rate in the lanthanum and $\mathrm{CC}$ groups after a one-year treatment. None of these trials found association with aluminium-like bone toxicity after treatment of lanthanum. A standard and uniform evaluation system for bone disorder in CKD-MBD must be established to improve the assessment of the effects of LC on ROD.

Sevelamer is another calcium- and aluminum-free phosphate binder. A small number of studies directly compared this binder with LC. Only two cross-over studies were identified, and our meta-analysis showed that the two treatments were similarly effective in controlling serum calcium and phosphorus levels. However, compared with LC, SH can improve the lipid profile by reducing the total cholesterol and LDL levels. SH differs from other phosphate binders because of its unique ability to reduce the levels of serum cholesterol and proinflammatory factors. However, it also increases the risks of hyperchloremic metabolic acidosis and hyperkalemia. Sevelamer binds to bile acids probably because of its physiochemical similarities to common bile sequestrants. This characteristic allows sevelamer to interfere with fat absorption and reduce LDL cholesterol levels [45]. In addition, sevelamer can physicochemically bind to the negatively charged lipid A portion of endotoxin (ET). In vitro experiments showed that $\mathrm{SH}$ can bind to ET in a dose-dependent manner [46]. Moreover, an in vivo experiment demonstrated that sevelamer can reduce ET which was triggered by renal failure [47]. Previous trials [48-50] showed that compared with calcium-containing phosphate binders, sevelamer reduces the levels ET and proinflammatory markers such as CRP, interlekin-6, endothelin-1, and plasminogen activator inhibitor-1 in dialysis patients. In patients with early diabetic CKD, sevelamer carbonate significantly reduces HbA1c, fibroblast growth factor 23, lipids, tumor necrosis factor- $\alpha$, and oxidative stress compared with CC [51]. However, the studies included in our systematic review did not compare the anti-inflammatory effects of LC and $\mathrm{SH}$. Compelling preliminary data demonstrate that the ET-binding effect and anti-inflammatory activity of $\mathrm{SH}$ are associated with the improvement of mortality in ESRD compared with those of calcium-containing phosphate binders [52]. Long-term clinical trials must be conducted to confirm the relationship between the amelioration of lipid metabolism and the improvement of patient survival. In particular, we recommend that additional studies be performed to determine if the lipid-lowering effect or anti-inflammatory activity of $\mathrm{SH}$ can improve the clinical outcome for CKD-MBD patients compared with LC.

The included studies did not compare the serum bicarbonate and potassium levels of the different groups. Moreover, the risks of acidosis and hyperkalemia of $\mathrm{SH}$ were unknown. Sevelamer carbonate is an improved, buffered form of $\mathrm{SH}$ that has equivalent efficacy in controlling phosphate levels but has a lower incidence of the above adverse effects [53]. Future RCTs that compare LC and sevelamer carbonate is also recommended.

The safety of LC has received considerable concern. All of the studies included in this paper reported that the accumulation of LC in both blood and bone was below toxic levels. After six years of LC treatment, the incidences of fractures and bone-related musculoskeletal adverse events were also significantly low [54]. In addition to that in bone, lanthanum accumulation in the liver should also be a point of concern because LC is excreted through bile. Although increased liver lanthanum deposition after oral lanthanum loading in uremic rats in comparison with normal renal function rats was observed 
$[55,56]$, a subsequent investigation showed that lanthanum was present in the lysosomes of hepatocytes and was mostly concentrated in the biliary poles of the hepatocytes and within the bile canaliculi [57]. No lanthanum was detected in the hepatocyte mitochondria, nucleus, or cytoplasm. The six-year, long-term clinical observation also showed that liver enzymes did not increase, and that the few cases of liver- or biliary-related adverse events, none of which were considered to be related to lanthanum, were mainly observed in the first two years of treatment [54]. However, one case study reported that lathanum induced abnormal liver function in one male patient with PD and in one female patient with HD [58]. Our systematic review cannot provide sufficient evidence to show the safety of lanthanum in liver function. Therefore, future studies should also investigate the concentration and possible toxicity of lanthanum in the liver.

The most commonly reported side effects were gastrointestinal adverse events. Our meta-analysis showed no differences in nausea, constipation, and dyspepsia. The prevalence of vomiting was significantly higher in LC compared with that in CC. LC had lower risks of diarrhea and intradialytic hypotension compared with placebos and previous phosphate binders, respectively. Other side effects included dialysis complications, bronchitis, rhinitis, and pruritus while no significant differences were found between the treatments. One study showed that LC-treated patients had lower risks of intradialytic hypotension, diarrhea, cramps or myalgia, and abdominal pain compared with those treated with their previous phosphate binders.

Note that the effects of the dialysis type, dialysis dose, session duration, membrane type, and dialytic modality on phosphate removal were not assessed in the metaanalysis. Only four trials included patients with peritoneal dialysis. Therefore additional RCTs should be conducted to investigate the effects of lanthanum in peritoneal-dialysis patients.

To our knowledge, this study is the first to conduct a comprehensive systematic review of RCTs that assessed the advantages and disadvantages of using lanthanum treatment for CKD-MBD in dialysis patients. A previous [25] systematic review evaluated the effects of all phosphate binders on CKD-MBD in patients with CKD and also confirmed the efficacy of lanthanum in reducing the phosphorus levels (similar to that of CC) and lowering the incidence of hypercalcemia. However, the study did not evaluate the effects of lanthanum on mortality, vascular calcification, and bone disorder. Moreover, it did not provide the detailed side effects of lanthanum on bone, plasma, and liver contents nor include peritonealdialysis patients. Other published meta-analyses focused only on $\mathrm{SH}$ [59] or included both observational studies and RCTs [60].
Our systematic review has a number of limitations. Except for two trials with large sample sizes of 1359 [23] and 767 [31], most of the trials enrolled a limited number of patients. The duration of half of these trials ranged from 4 weeks to 8 weeks. The key findings are limited by the lack of long-term studies on mortality, cardiovascular events, cardiovascular calcification, and bone disorder. Most of the included trials only observed the biochemical parameters without considering patientfocused outcomes. Moreover, this review did not evaluate the health economic effectiveness of LC. Although LC can reduce the serum phosphorus level and has a lower risk of vascular calcification and hypercalcemia, it is a rare metal that is more valuable than calcium. A number of studies focused on the cost-effectiveness ratio of phosphate binders [61,62]. One study [61] showed that LC is cost-effective as a second-line treatment for patients who are not adequately maintained on $\mathrm{CC}$ (serum phosphorus above $5.6 \mathrm{mg} / \mathrm{dL}$ ). Therefore, a systematic review that evaluates the health economic effectiveness of LC must be conducted to serve as a guideline for clinicians in providing individualized therapies for different patients, particularly for those in developing countries.

\section{Conclusions}

The results of this meta-analysis show that lanthanum efficiently lowers the serum phosphorous and $\mathrm{iPTH}$ levels without elevating the serum calcium level. Apart from a higher incidence of vomiting, LC did not demonstrate higher incidence rates of other adverse effects compared with other treatments. Moreover, the accumulation of LC in blood and bone was below toxic levels. Current evidence is insufficient to demonstrate that lanthanum is superior to other phosphate binders in terms of lowering mortality, cardiovascular events, and vascular calcification as well as of improving bone disorder. Future studies with larger sample sizes and longer durations must be conducted to assess the effects of lanthanum on not only biochemical outcomes, but also on mortality, cardiovascular events, vascular calcification, and bone disorder. In addition, comparison with sevelamer carbonate, safety in bone and liver, health economic effectiveness, dialysis method and prescription should also be concerned in the future studies with LC.

\section{Abbreviations}

CKD-MBD: Chronic kidney disease mineral and bone disorder; ESRD:

End-stage renal disease; LC: Lanthanum carbonate; RCT: Randomized controlled trials; iPTH: Intact parathyroid hormone; CC: Calcium carbonate;

SH: Sevelamer hydrochlorid; CV: Cardiovascular; HD: Hemodialysis;

CAPD: Continuous ambulatory peritoneal dialysis; CENTRAL: Cochrane Central

Register of Controlled Trials; CBBs: Calcium-based binders; NCBs: Non-calcium binders; CT: Computed tomography; TAP: Total alkaline phosphatase;

BAP: Bone-specific alkaline phosphatase); RR: Risk ratios; Cl: Confidence intervals; MD: Mean difference; SMD: Standardised mean difference; ROD: Renal osteodystrophy; DCOR: Dialysis Clinical Outcomes Revisited. 


\section{Competing interests}

The authors declared that they have no competing interests.

\section{Authors' contributions}

ZCL was involved in conducting the literature searches, obtained and analysed studies and wrote the manuscript of the paper. WJ was involved in conducting the literature searches, obtained and analysed studies. LZ was involved in the design of the study, adjudication on disagreements in data analysis, writing and editing of draft and final versions of the paper. FJM was involved in the design of the study. All authors have read and approved the final manuscript.

\section{Acknowledgements}

The authors would like to acknowledge Professor Guanjian Liu in EvidenceBased Medicine Center of China, for his assistance in the conduct of this systematic review. The authors would also like to acknowledge Professor Takashi Shigematsu and Professor Maki Morikawa who provide the detailed data to this systematic review.

\section{Author details}

${ }^{1}$ Department of nephrology, West China Hospital of Sichuan University, Chengdu, China. ${ }^{2}$ Luzhou Medical College, Luzhou, China.

\section{Received: 23 April 2013 Accepted: 11 October 2013}

Published: 17 October 2013

\section{References}

1. Moe S, Drüeke T, Cunningham J, Goodman W, Martin K, Olgaard K, Ott S, Sprague S, Lameire N, Eknoyan G, Kidney Disease: Improving Global Outcomes (KDIGO): Definition, evaluation, and classification of renal osteodystrophy: a position statement from Kidney Disease: Improving Global Outcomes (KDIGO). Kidney Int 2006, 69:1945-1953.

2. Levin A, Bakris GL, Molitch M, Smulders M, Tian J, Williams LA, Andress DL: Prevalence of abnormal serum vitamin D, PTH, calcium, and phosphorus in patients with chronic kidney disease: results of the study to evaluate early kidney disease. Kidney Int 2007, 71(1):31-38.

3. Block GA, Pork FK: Re-evaluation of risks associated with hyperphosphatemia and hyperparathyroidism in dialysis patients: Recommendations for a change in management. Am J Kidney Dis 2000, 35:1226-1237.

4. Palmer SC, Hayen A, Macaskill P, Pellegrini F, Craig JC, Elder GJ, Strippoli GF: Serum levels of phosphorus, parathyroid hormone, and calcium and risks of death and cardiovascular disease in individuals with chronic kidney disease: a systematic review and meta-analysis. JAMA 2011, 305(11):1119-1127.

5. Wald R, Sarnak MJ, Tighiouart H, Cheung AK, Levey AS, Eknoyan G, Miskulin DC: Disordered mineral metabolism in hemodialysis patients: an analysis of cumulative effects in the Hemodialysis (HEMO) Study. Am J Kidney Dis 2008, 52:531-540.

6. Tentori F, Blayney MJ, Albert JM, Gillespie BW, Kerr PG, Bommer J, Young EW, Akizawa T, Akiba T, Pisoni RL, Robinson BM, Port FK: Mortality risk for dialysis patients with different levels of serum calcium, phosphorus, and PTH: the Dialysis Outcomes and Practice Patterns Study (DOPPS). Am J Kidney Dis 2008, 52:519-530.

7. Goodman WG: Medical management of secondary hyperparathyroidism in chronic renal failure. Nephrol Dial Transplant 2003, 18:2-8.

8. Ihle B, Becker G, Kincaid-Smith P: Clinical and biochemical features of aluminium-related bone disease. Kidney Int 1986, 29:S80-\$86.

9. Block G, Uribarri J, Coladonato JA, Fan SL, Cunningham J, Nolan CR, Qunibi WY, Lindberg JS: How should hyperphosphatemia be managed in dialysis patients? Semin Dial 2002, 15(5):315-328.

10. Goodman WG, Goldin J, Kuizon BD, Yoon C, Gales B, Sider D, Wang Y, Chung J, Emerick A, Greaser L, Elashoff RM, Salusky IB: Coronary-artery calcification in young adults with end-stage renal disease who are undergoing dialysis. N Engl J Med 2000, 342:1478-1483.

11. Bleyer AJ, Burke SK, Dillon M, Garrett B, Kant KS, Lynch D, Rahman SN, Schoenfeld P, Teitelbaum I, Zeig S, Slatopolsky E: A comparison of the calcium-free phosphate binder sevelamer hydrochloride with calcium acetate in the treatment of hyperphosphatemia in hemodialysis patients. Am J Kidney Dis 1999, 33:694-701.
12. Slatopolsky EA, Burke SK, Dillon MA: RenaGel, a nonabsorbed calcium- and aluminum-free phosphate binder, lowers serum phosphorus and parathyroid hormone. Kidney Int 1999, 55:299-307.

13. Brezina B, Qunibi WY, Nolan CR: Acid loading during treatment with sevelamer hydrochloride: mechanisms and clinical implications. Kidney Int Supp/ 2004, 9(90):S39-S45.

14. Braun J, Asmus HG, Holzer H, Brunkhorst R, Krause R, Schulz W, Neumayer $\mathrm{HH}$, Raggi P, Bommer J: Long-term comparison of a calcium-free phosphate binder and calcium carbonate - phosphorus metabolism and cardiovascular calcification. Clin Nephrol 2004, 62:104-115.

15. Locatelli F, D’Amico M, Pontoriero G: Lanthanum carbonate. Drugs 2003, 6:688-695.

16. Behets GJ, Verberckmoes SC, D'Haese PC, de Broe ME: Lanthanum carbonate: a new phosphate binder. Curr Opin Nephrol Hypertens 2004, 13:403-409.

17. Finn WF, Joy MS, Hladik GA, And the Lanthanum Study Group: Efficacy and safety of lanthanum carbonate for reduction of serum phosphorus in patients with chronic renal failure receiving hemodialysis. Clin Nephrol 2004, 62:193-201.

18. Hutchison AJ, Speake M, Al Baaj F: Reducing high phosphate levels in patients with chronic renal failure undergoing dialysis: a 4-week, dosefinding, open-label study with lanthanum carbonate. Nephrol Dial Transplant 2004, 19:1902-1906.

19. Toussaint ND, Lau KK, Polkinghorne KR, Kerr PG: Attenuation of aortic calcification with lanthanum carbonate versus calcium-based phosphate binders in haemodialysis: A pilot randomized controlled trial. Nephrology (Carlon) 2011, 16:290-298.

20. Haese PC, Spasovski GB, Sikole A, Hutchison A, Freemont TJ, Sulkova S, Swanepoel C, Pejanovic S, Djukanovic L, Balducci A, Coen G, Sulowicz W, Ferreira A, Torres A, Curic S, Popovic M, Dimkovic N, de Broe ME: A multicenter study on the effects of lanthanum carbonate (Fosrenol) and calcium carbonate on renal bone disease in dialysis patients. Kidney Int Supp/ 2003, 6(85):S73-S78.

21. Malluche HH, Siami GA, Swanepoel C, Wang GH, Mawad H, Confer S, Smith M, Pratt RD, Monier-Faugere MC: SPD405-307 Lanthanum Carbonate Study Group: Improvements in renal osteodystrophy in patients treated with lanthanum carbonate for two years. Clin Nephrol 2008, 70:284-295.

22. Spasovski GB, Sikole A, Gelev S, Masin-Spasovska J, Freemont T, Webster I, Gill M, Jones C, De Broe ME, D'Haese PC: Evolution of bone and plasma concentration of lanthanum in dialysis patients before, during 1 year of treatment with lanthanum carbonate and after 2 years of follow-up. Nephrol Dial Transplant 2006, 21:2217-2224.

23. Finn WF, SPD 405-307 Lanthanum Study Group: Lanthanum carbonate versus standard therapy for the treatment of hyperphosphatemia: safety and efficacy in chronic maintenance hemodialysis patients. Clin Nephrol 2006, 65:191-202.

24. Wilson R, Zhang P, Smyth M, Pratt R: Assessment of survival in a 2-year comparative study of lanthanum carbonate versus standard therapy. Current Medical Research \& Opinion 2009, 25:3021-3028.

25. Navaneethan SD, Palmer SC, Craig JC, Elder GJ, Strippoli GF: Benefits and harms of phosphate binders in CKD: a systematic review of randomized controlled trials. Am J Kidney Dis 2009, 54:619-637.

26. Higgins JPT, Green S: Cochrane Handbook for Systematic Reviews of Interventions Version 5.0.0 [updated February 2008]. The Cochrane Collaboration 2008: Editors Available from www.cochrane-handbook.org

27. Altmann P, Barnett ME, Finn WF: Cognitive function in Stage 5 chronic kidney disease patients on hemodialysis: no adverse effects of lanthanum carbonate compared with standard phosphate-binder therapy. Kidney Int 2007, 71:252-259.

28. Mehrotra R, Martin KJ, Fishbane S, Sprague SM, Zeig S, Anger M, Fosrenol Overview Research Evaluation Study for Early Experience Study Group: Higher strength lanthanum carbonate provides serum phosphorus control with a low tablet burden and is preferred by patients and physicians: a multicenter study. J Am Soc Nephrol 2008, 3:1437-1445.

29. Toida T, Fukudome K, Fujimoto S, Yamada K, Sato Y, Chiyotanda S, Kitamura K: Effect of lanthanum carbonate vs. calcium carbonate on serum calcium in hemodialysis patients: a crossover study. Clin Nephrol 2012, 78:216-223.

30. Alastair Hutchison J, Bart M, Johan V, Gernot A, Elfatih M, Roland S, Wolfgang B, Rene J, Andre V: Long-Term Efficacy and Tolerability of Lanthanum Carbonate: Results from a 3-Year Study. Nephron Clin Pract 2006, 102:61-71. 
31. Hutchison AJ, Maes B, Vanwalleghem J, Asmus G, Mohamed E, Schmieder R, Backs W, Jamar R, Vosskuhler A: Efficacy, tolerability, and safety of lanthanum carbonate in hyperphosphatemia: a 6-month, randomized, comparative trial versus calcium carbonate. Nephron Clin Pract 2005, 100:8-19.

32. Sprague SM, Ross EA, Nath SD, Zhang P, Pratt RD, Krause R: Lanthanum carbonate vs. sevelamer hydrochloride for the reduction of serum phosphorus in hemodialysis patients: a crossover study. Clin Nephrol 2009, 72:252-258.

33. Kasai S, Sato K, Murata Y, Kinoshita Y: Randomized crossover study of the efficacy and safety of sevelamer hydrochloride and lanthanum carbonate in Japanese patients undergoing hemodialysis. Ther Apher Dial 2012, 16:341-349.

34. Shigematsu T, and the Lanthanum Carbonate Research Group: Lanthanum carbonate effectively controls serum phosphate without affecting serum calcium levels in patients undergoing hemodialysis. Ther Apher Dial 2007, 12:55-61.

35. Shigematsu T, And the Lanthanum Carbonate Group: Multicenter prospective randomized, double-blind comparative study between lanthanum carbonate and calcium carbonate as phosphate binders in Japanese hemodialysis patients with hyperphosphatemia. Clin Nephrol 2008, 70:404-410.

36. Al-Baaj F, Speake M, Hutchison AJ: Control of serum phosphate by oral lanthanum carbonate in patients undergoing hemodialysis and continuous ambulatory peritoneal dialysis in a short-term, placebocontrolled study. Nephrol Dial Transplant 2005, 20:775-782.

37. Joy MS, Finn WF: Randomized, double-blind, placebo-controlled, dosetitration, phase III study assessing the efficacy and tolerability of lanthanum carbonate: a new phosphate binder for the treatment of hyperphosphatemia. Am J Kidney Dis 2003, 42:96-107.

38. Chiang SS, Chen JB, Yang WC: Lanthanum carbonate (Fosrenol) efficacy and tolerability in the treatment of hyperphosphatemic patients with end-stage renal disease. Clin Nephrol 2005, 63:461-470.

39. Lee YK, Choi HY, Shin SK, Lee HY: Effect of lanthanum carbonate on phosphate control in continuous ambulatory peritoneal dialysis patients in Korea: a randomized prospective study. Clin Nephro/ 2013, 79(2):136-142.

40. Jing X, Yi-Xiang Z, Xue-Qing Y, Zhi-Hong L, Li-Ning W, Jiang-Hua C, Ya-Ping F, Zhao-Hui N, Mei W, Fa-Huan Y, Guo-Hua D, Xiang-Mei C, Ai-Ping Z, Chang-Lin M: Lanthanum carbonate for the treatment of hyperphosphatemia in CKD 5D: multicenter, double blind, randomized, controlled trial in mainland China. BMC Nephrol 2013, 14:29.

41. Suki W, Zabaneh R, Cngiano J, Reed J, Fischer D, Garrett L, Ling BN, ChasanTaber S, Dillon MA, Blair AT, Burke SK: Effects of sevelamer and calciumbased phosphate binders on mortality in hemodialysis patients. Kidney Int 2007, 72(9):1130-1137.

42. Salgueira M, del Toro N, Moreno-Alba R, Jiménez E, Aresté N, Palma A: Vascular calcification in the uremic patient: a cardiovascular risk? Kidney Int Supp/ 2003, 6(86):S119-S121.

43. Nikolov IG, Joki N, Nguyen-Khoa T, Guerrera IC, Maizel J, Benchitrit J, Machado Dos Reis L, Edelman A, Lacour B, Jorgetti V, Drüeke TB, Massy ZA Lanthanum carbonate, like sevelamer- $\mathrm{HCl}$, retards the progression of vascular calcification and atherosclerosis in uremic apolipoprotein Edeficient mice. Nephrol Dial Transplant 2012, 27(2):505-513.

44. Rodriguez M, Guerrero F, Lopez I, Aguilera-Tejero E, Rodriguez M: Lanthanum carbonate and sevelamer hydrochloride prevent vascular calcification in uremic rats. J Am Soc Nephrol 2008, 19:164A.

45. Braunlin W, Zhorov E, Guo A, Apruzzese W, Xu Q, Hook P, Smisek DL, Mandeville WH, Holmes-Farley SR: Bile acid binding to sevelamer $\mathrm{HCl}$. Kidney Int 2002, 62(2):611-619.

46. Perianayagam MC, Jaber BL: Endotoxin-binding affinity of sevelamer hydrochloride. Am J Nephrol 2008, 28(5):802-807.

47. Hauser AB, Azevedo IR, Gonçalves S, Stinghen A, Aita C, Pecoits-Filho R: Sevelamer carbonate reduces inflammation and endotoxemia in an animal model of uremia. Blood Purif 2010, 30(3):153-158.

48. Stinghen AE, Gonçalves SM, Bucharles S, Branco FS, Gruber B, Hauser AB, Pecoits-Filho R: Sevelamer decreases systemic inflammation in parallel to a reduction in endotoxemia. Blood Purif 2010, 29(4):352-356.

49. Navarro-González JF, Mora-Fernández C, Muros De Fuentes M, DonateCorrea J, Cazaña-Pérez V, García-Pérez J: Effect of phosphate binders on serum inflammatory profile, soluble CD14, and endotoxin levels in hemodialysis patients. Clin J Am Soc Nephrol 2011, 6(9):2272-2279.
50. Chennasamudram SP, Noor T, Vasylyeva TL: Comparison of sevelamer and calcium carbonate on endothelial function and inflammation in patients on peritoneal dialysis. J Ren Care 2013, 39(2):82-89.

51. Vlassara H, Uribarri J, Cai W, Goodman S, Pyzik R, Post J, Grosjean F, Woodward M, Striker GE: Effects of sevelamer on HbA1c, inflammation, and advanced glycation end products in diabetic kidney disease. Clin J Am Soc Nephrol 2012, 7(6):934-942.

52. Koenig W, Khuseyinova N, Hoffmann MM, März W, Fröhlich M, Hoffmeister A, Brenner $H$, Rothenbacher D: D14 C(-260) T polymorphism, plasma levels of the soluble endotoxin receptor CD14, their association with chronic infections and risk of stable coronary artery disease. J Am Coll Cardiol 2002, 40(1):34-42.

53. Delmez J, Block G, Robertson J, Chasan-Taber S, Blair A, Dillon M, Bleyer AJ: A randomized, doubleblind, crossover design study of sevelamer hydrochloride and sevelamer carbonate in patients on hemodialysis. Clin Nephrol 2007, 68:386-391.

54. Hutchison AJ, Barnett ME, Krause R, Kwan JT, Siami GA, SPD405-309 Lanthanum Study Group: Long-term efficacy and safety profile of lanthanum carbonate: results for up to 6 years of treatment. Nephron Clin Pract 2008, 110(1):c15-c23.

55. Slatopolsky E, Liapis H, Finch J: Progressive accumulation of lanthanum in the liver of normal and uremic rats. Kidney Int 2005, 68(6):2809-2813.

56. Lacour B, Lucas A, Auchere D, Ruellan N, Serre Patey NM, Drueke TB: Chronic renal failure is associated with increased tissue deposition of lanthanum after 28-day oral administration. Kidney Int 2005, 67(3):1062-1069.

57. Yang Z, Schryvers D, Roels F, D'Haese PC, De Broe ME: Demonstration of lanthanum in liver cells by energy-dispersive X-ray spectroscopy, electron energy loss spectroscopy and high-resolution transmission electron microscopy. J Microsc 2006, 223(Pt 2):133-139.

58. Namagondlu G, Main N, Yates L, Mooney J, Sathyamurthy S, Daryanani I, Crowe A, Ledson T, Banerjee A: Lanthanum associated abnormal liver function tests in two patients on dialysis: a case report. J Med Case Rep 2009, 9(3):9321.

59. Manns B, Stevens L, Miskulin D, Owen WF Jr, Winkelmayer WC, Tonelli M: A systematic review of sevelamer in ESRD and an analysis of its potential economic impact in Canada and the United States. Kidney Int 2004, 66(3):1239-1247.

60. Burke SK, Dillon MA, Hemken DE, Rezabek MS, Balwit JM: Meta-analysis of the effect of sevelamer on phosphorus, calcium, PTH, and serum lipids in dialysis patients. Adv Ren Replace Ther 2003, 10(2):133-145.

61. Brennan A, Akehurst R, Davis S, Sakai H, Abbott V: The cost-effectiveness of lanthanum carbonate in the treatment of hyperphosphatemia in patients with end-stage renal disease. Value Health 2007, 10(1):32-41.

62. Brunner-Ziegler S, Fröschl B, Hiebinger C, Zsifkovits J: Effectiveness and cost-efficacy of phosphate binders in hemodialysis. Ann Nutr Metab 2011, 58(4):315-319.

doi:10.1186/1471-2369-14-226

Cite this article as: Zhang et al:: Efficacy and safety of lanthanum carbonate on chronic kidney disease-mineral and bone disorder in dialysis patients: a systematic review. BMC Nephrology 2013 14:226.

\section{Submit your next manuscript to BioMed Central and take full advantage of:}

- Convenient online submission

- Thorough peer review

- No space constraints or color figure charges

- Immediate publication on acceptance

- Inclusion in PubMed, CAS, Scopus and Google Scholar

- Research which is freely available for redistribution 